Anna-Karin Westman is a PhD student at Umeå University and Mid Sweden University. Her main research interest is the contribution of peer discussions to the teaching and learning of biology. Anna-Karin Westman obtained her teaching degree in biology and chemistry in 1993 and worked in a Swedish upper secondary school until 2008, when she started her research studies. In 2011 she obtained a licentiate degree in Science Education.

\title{
Investigation of Peer Discussions on Genetic Concepts
}

\begin{abstract}
This study is an investigation on how students express their understanding of genetic concepts and their relations during peer discussions. Participants in this study were non-major students from a Swedish upper secondary school. Special attention was paid to how the groups treated the domain-specific vocabulary, how they expressed their understanding of reduction division and how they connected concepts from different biological organization levels. These subject areas have been reported as difficult for students in earlier studies. The results show discussions concerning the three subject areas and in the discussions the students help each other to make the meaning of the genetic concepts clear. The analysis is based on socio-cultural perspectives with focus on how the participants treated the genetic content from the previously presented subject areas in their discussions.
\end{abstract}

\section{INTRODUCTION}

This paper reports on a study addressing group discussion as a part of teaching and learning genetics among non-majors in the Swedish upper secondary school. Students' difficulties in genetics are well documented in the research on biology education. The difficulties include the extensive domainspecific vocabulary and the problems students have to see relationships between visible phenomena and molecular processes concerning DNA and chromosomes (Bahar, Johnstone \& Suttcliffe, 1999; Wood-Robinson, Lewis \& Leach, 2000; Marbach-Ad \& Stavy, 2000; Dreyfus \& Jungwirth, 1989).

\section{Research on students' understandings and misunderstandings of genetics}

In biology education research, the teaching and learning of genetics has been investigated thoroughly. Difficulties in understanding genetics have been ascribed to several reasons. Knippels (2002) lists five main causes for these problems, of which three are addressed in this study.

First, there is the domain-specific vocabulary and terminology. When students come in touch with genetics as a school subject they practically drown in new concepts that are central to the subject. Being familiar with the definitions of the words improves the possibility to succeed in learning genetics and students have declared that the large amount of new words is one obstacle (Bahar, Johnstone \& Hansell, 1999).

The second problem is how the gametes arise. There is a difference between ordinary cell division (mitosis) and the cell division that creates gametes (meiosis). This causes confusion among students. 
An important source for this confusion is a lack of understanding of how concepts relate to each other, e.g. the relationship between chromosomes in a gamete and in a fertilised egg (Wood-Robinson et al., 2000). Another study shows differences between the understanding of mitosis and that of meiosis, and verifies that it is easier for students to understand the mechanism behind the first one (MarbachAd \& Stavy, 2000).

The fact that the concepts also represent different levels of biological organization constitutes the third problem. The biological organization levels are only partially visible. Learners can see the multicellular organism and experience events on the multicellular level. With a microscope, the cells and chromosomes can be visible, but the processes in the cell can still not be seen. The learners' inability to relate the processes on the molecular and cellular levels to relevant scientific problems causes difficulties to learn new scientific facts (Dreyfus \& Jungwirth, 1989). Three levels of organization that are central in the teaching and learning of genetics are the visible, macroscopic level, the microscopic level and the sub-microscopic level. This multi-level conceptualization has been reported to cause difficulties in different parts of science education, for example in the case of chemistry (Johnstone, 1991). In the case of genetics, one needs knowledge about chromosomes and cell division to be able to give a scientifically accepted explanation to why characteristics move from parents to offspring. During an investigation of students' cognitive structures in elementary genetics by the use of word association tests, the results showed the strongest interconnectedness between chromosome and gene, two words which belong to the microscopic and sub-microscopic levels. Much weaker interconnectedness was shown between gene and phenotype, which demand an association between the sub-microscopic and macroscopic levels (Bahar, Johnstone \& Suttcliffe, 1999). In the same test, the interconnectedness between cell division and gamete was estimated as weak, which confirms the problem to understand how gametes arise.

The two remaining problems presented by Knippels, the mathematical nature of Mendelian genetic tasks and the abstract nature due to the sequencing of the biological curriculum, are not explicitly addressed in this study.

\section{Peer discussions}

Peer discussion has a positive influence on learning, e.g. individuals' performance in the case of concept questions concerning genetics improves after peer discussions (Smith et al., 2009). Results show improvement both in groups with and without participants who manage to solve the question before discussion. This indicates that improved results are not only a copy of the answer from a student with more knowledge in the subject, but that they emerge from the discussion in itself. Student opinions also support this conclusion by stressing the fact that if someone in the group knows the right answer, this can restrain the discussion (ibid.). In a survey including six thousand students, their learning outcomes from traditional courses were compared to the learning outcomes of students participating in courses that used interactive engagement methods. Interactive engagement (IE) methods include methods that promote the interactive engagement of students by activities which give immediate feedback in discussions including peers and/or instructors (Hake, 1998). The results show significantly higher outcomes with IE methods both in a conceptual test and in a test on problem solving. IE does not necessarily include the opportunity to argue individual opinions; it could also be an opportunity to discuss interpretation on parts of the scientific content. Jonathan Osborne states in a review of recent science education research that the absence of opportunities to practice argumentation in contemporary science education is a significant weakness (Osborne, 2010).

\section{Science studies and socio-cultural perspectives}

This study investigates a learning situation where students have an opportunity to apply their joint knowledge in genetics on a new problem. From a socio-cultural point of view, learning science involves acquainting oneself with both the scientific content and the scientific language. The content is 
the scientific point of view, which often involves new, scientific explanations to familiar phenomena. One of the aims of science education is to introduce the student to the social language of science. The teacher's role in science education is therefore to equip the student with a useful toolkit of ways of talking and knowing about science (Mortimer \& Scott, 2003). This does not differ from any other school subject.

\section{Central aims and Research ouestions}

The central aim in this study was to investigate how students expressed their understanding of central concepts and processes concerning genetics. The assignment for the students was designed to specifically address the domain-specific vocabulary, how gametes arise and relationships between concepts from different organization levels. Here, the aim was to see how the students express their understanding of the documented genetic difficulties presented above. To see if these aims are fulfilled, the following research questions were posed:

How do the students express their understanding of the domain specific vocabulary?

How do the students express their understanding of how gametes form?

How do the students express their understanding of relationships between concepts from different organization levels?

\section{DESIGN OF THE TEACHING AND LEARNING ACTIVITY}

The data collection for this study took place in a Swedish upper secondary school. The students attended an optional course in natural science and they were all non-majors in science. Genetics was studied as a part of this course and before this study was carried out, the genetic concepts were presented to the class during whole-class lessons with their ordinary teacher and by individual work on answering written questions in the classroom.

In addition to this, after four lessons (6o minutes) of genetic studies, the students completed a group assignment where they constructed a concept map (Novak \& Cañas, 2008). The class was divided into four groups, three with three students in each group and one with four students. The assignment was first introduced by a presentation of the program CMapTools (Novak \& Cañas, 2008). During the next lesson, the students worked in groups and decided through a discussion which would be the best way to join 20 selected genetic concepts and phrases in a map to answer a given question (Table 1). The task was posed as: Hereditary disposition for freckles is dominant. How can two parents with freckles have a child who has no freckles? Between the concepts in the map, the group agreed upon a word or phrase to explain their relationship. The selection of the concepts was made by the researcher and represented the content from earlier lessons. Each discussion was audio taped.

Table 1. Genetic concepts from the student assignment divided into biological organization levels.

\begin{tabular}{|c|c|c|}
\hline \multicolumn{3}{|c|}{$\begin{array}{l}\text { Question for the assignment: Hereditary disposition for freckles is dominant. How can two parents } \\
\text { with freckles have a child who has no freckles? }\end{array}$} \\
\hline Macroscopic & Microscopic & Sub-microscopic \\
\hline $\begin{array}{l}\text { Parents } \\
\text { Have freckles } \\
\text { No freckles } \\
\text { Child } \\
\text { Looks/characteristics }\end{array}$ & $\begin{array}{l}\text { Ordinary cell division (mitosis) } \\
\text { Reduction division (meiosis) } \\
\text { Fertilized egg } \\
\text { Chromosomes } \\
\text { Ovum } \\
\text { Sperm }\end{array}$ & $\begin{array}{l}\text { Recessive hereditary, no freckles } \\
\text { Dominant hereditary, freckles } \\
\text { Protein } \\
\text { DNA } \\
\text { mRNA } \\
\text { tRNA } \\
\text { Gene } \\
\text { Amino acids } \\
\text { Copy itself }\end{array}$ \\
\hline
\end{tabular}


The reason for choosing concept mapping in this study was because it is an activity that gives students an opportunity to think through the meaning of concepts and also give students an opportunity to relate a concept to other important concepts in a subject area (Wellington \& Osborne, 2001). Here, the activity was carried out in small groups to encourage the participants to formulate and explain their understanding of the selected concepts. Weaknesses of this assignment would be if student groups did not find important connections between concepts or if not all students in the group would get an opportunity to express their opinions.

\section{RESEARCH DESIGN AND METHODOLOGY}

In this study, students were introduced to an assignment which included important concepts from their genetics course. By choosing central concepts and by letting the students accomplish the assignment in small groups, the participants had an opportunity to discuss their understanding of the concepts. This assignment was performed with the intention to help students to relate molecular concepts to visible, macroscopic concepts and clarify meanings of central concepts to address the previously known difficulties. Interactive engagement and peer discussion have proved themselves to enhance learning. The design of the assignment in this study gives the students an opportunity to argue for their own meaning making (Mortimer \& Scott, 2003) and get immediate feedback from peers in a peer discussion in the context of genetics.

The students $(18-19$ years, $n=13)$ formed four groups by giving them a random figure and by gathering all students with the same figure in one group. The research project was presented when the learning activity was introduced. The learning activity was accomplished as a compulsory activity, but the students were told that their participation in the recordings and the following research were voluntary.

All recordings were transcribed and the parts with a content concerning the previously presented genetic difficulties were analysed by two researchers in respect to how the student treated the known difficulties. In a first reading of the transcripts, all parts that included discussions about the three previously presented genetic difficulties were identified. The focus of the analysis was any possible progress made by the groups in the discussion of conceptual understanding. All parts of the discussions that concerned the three research questions were copied into a table with the subject for the question written next to them. Findings from the four groups were then compared for each genetic topic and differences and similarities were identified.

\section{RESULTS}

All findings were grouped into the three genetic difficulties in the first step of the analysis and are also reported under three subheadings here. Students are anonymous and numbered in the excerpts. The first number is the group and the second number is the number of the student.

\section{Understanding of the domain specific vocabulary}

Discussions about the meaning of the genetic vocabulary are present in several parts of the transcripts. There is a difference in how the groups succeed in making the meanings of concepts clear. One group had a fruitful discussion concerning alleles. The scientific idea about heredity and how the alleles exist in pairs in somatic cells are discussed by the group, although the word allele is missing in the discussion.

$\mathbf{1}$ S3:3 Both [parents' recessive trait] are transferred to the child.

$2 \mathrm{~S} 3: 1 \mathrm{Mm}$

3 S3:2 But then the dominant trait must have gone somewhere else?

[...]

9 S3:3 Yes, it is the same; both [parents] have one trait for freckles and one for not getting freckles. 
10 S3:2 But then we have to explain why it's like that.

[...]

14 S3:2 [...] It just shows that the child has no freckles, it doesn't say anything about why.

$\mathbf{1 5}$ S:1 But it's because it's a recessive trait, which is transferred to the child.

The reason why a characteristic does not manifest itself in one generation, but does in the next generation becomes clearer during the group talk. In turn 9, S3:3 makes this clear to the rest of the group and in turn 15, S3:1 explains it a bit further. Another group has more difficulties. They have problems with the difference between alleles and how the traits manifest in the next generation.

$2 \mathrm{~S} 4: 2$ If we say, like, capital $\mathrm{S}$ is a dominant trait and lower-case $\mathrm{s}$ is recessive and ...

$3 \mathrm{~S} 4: 3$ But he said, didn't he say that freckles are dominant?

$4 \mathrm{~S} 4: 1 \mathrm{Mm}$

$5 \mathrm{~S} 4: 3$ Can you have two dominant traits?

$[\ldots]$

$14 \mathrm{~S} 4: 3$ Yes, but then, if they have one dominant trait and freckles, than they have, then it is a greater probability, because then the dominant trait takes over.

One student, S4:3, never expresses an evident understanding of the difference between alleles and the manifest characteristic. Instead, in turn 14, he seems to think the dominant trait and freckles can be separated from each other. DNA, gene and chromosome and the connection between these concepts are discussed by all groups, and the participants most often help each other to understand their scientific meaning. A suitable phrase to explain the connection between gene and DNA is discussed in the next excerpt.

$1 \mathrm{~S} 1: 1$ But genes are a part of DNA, or?

2 S1:2 You don't have to write something in between [the concepts] or?

$3 \mathrm{~S} 1: 3$ No..?

4 S1:1 Write that: genes are part of DNA

S1:1's suggestion is accepted by the group and they wrote the phrase on their map. Students in the next example inspire each other to make an analogy that is tangible, but not in accordance with the scientific view (turn 2).

$1 \mathrm{~S} 4: 3$ Chromosomes are those tubes that are inside the nucleus, these are the chromosomes [points at a picture in the book], these two chromosomes are for eye color and those genes are, this one is for brown eye color and this one is for blue eye color, it is not in the chromosome [refers to the example in their book].

2 S4:1 No, it is like a test tube with a "part gene" in.

$3 \mathrm{~S} 4: 3$ Yes, but it can be other things than the ones in the school books... it can happen in different places.

$4 \mathrm{~S} 4: 2$ But isn't DNA the chromosome?

$5 \mathrm{~S} 4: 3$ Yes.

Test tube is more familiar than chromosome. S4:3 shows an understanding for the scientific concepts DNA, chromosome and gene later in their discussion. He expresses their connection in this way:

S4:3 Chromosomes contain DNA and they decide what the genes look like and they decide genes which decide looks and characteristics.

To sum up the four groups discussions, considering subject specific vocabulary, all of them include large parts where more than one participant express his or her view and where the expressions come closer to the meaning of the scientific concept during the groups' talk. 


\section{Understanding of how gametes form}

A central part for understanding heredity is to make the difference between mitosis and meiosis clear. It is closely connected to the discussion above; the understanding is required to make out why recessive dispositions manifest themselves in the next generation. Gamete formation is frequently discussed in the groups and pieces of understanding are added to each other, as shown by the next excerpt.

$1 \mathrm{~S} 3: 2$ [...] Does the meiosis take place in the chromosomes then? Or what..?

2 S3:1 Well, yes, you have two [= a pair] of each chromosome.

$3 \mathrm{~S} 3: 2$ Yes.

4 S3:1 But only half are transferred to the children.

$5 \mathrm{~S} 3: 2$ Yes.

6 S3:1 Otherwise the child would have twice the number of chromosomes.

7 S3:2 Yes....and that's the meiosis?

8 S3:1 Yes.

[...]

12 S3:3 A woman and a man, who both are heterozygote, they have one trait [of each kind].

[...]

14 S3:1 [...] Since the woman and the man have two variants of gametes, they can be combined in four ways. That's meiosis.

In turn 2, S3:1 explains the state in somatic cells, as a start to explain their difference from gamete cells. S3:2 starts to understand the mechanism of reduction division (turn 7) and also claims to understand the process later in the discussion. This vital part for learning genetics has become clearer to the student $S_{3}: 2$ in this group. Both $S_{3}: 3$ (turn 12) and $S_{3: 1}$ (turn 14) express themselves in accordance with the scientific view. The next group discussed the difference between the two types of cell division frequently.

1 S1:2 Yes, germ cells...

[connects germ cells to fertilized egg]

[...]

$8 \mathrm{~S} 1: 1$... then it, yes, then it divides? No...

9 S1:3 It isn't...

10 S1:1 (laughs)... what is really happening... yes, but if it divides, then there has to be more than one child... it can't divide..? I don't get it...

In turn 10 the word division is interpreted as something that yields more than one piece.

The next excerpt is from the end of their discussion and time is running out. The group never comes to any conclusion about the difference, but $\mathrm{S} 1: 2$ is starting to formulate a sentence about the special case of germ cells (turn 10).

1 S1:1 Isn't it the fertilized egg that starts to divide?

[...]

5 S1:1 Meiosis?

$6 \mathrm{~S} 1: 2$ Yes.

$7 \mathrm{~S} 1: 1$ But the ordinary cell division, where..?

$8 \mathrm{~S} 1: 2$ It happens in the rest of the body.

9 S1:1 Yes, but, it occurs when the child has been made, then a regular [division] starts..?

10 S1:2 Is it only the germ cells that are distributed..?

$11 \mathrm{~S} 1: 3$ No...

At least S1:2 started to discuss the difference between the divisions of the two cell types although the group had to finish before they had come to a conclusion. One of the group members' expressions are 
closer to the scientific view. Common for all of the four groups are discussions about gamete formation and the difference from ordinary cell division. The group that came closest to the scientific view is the first in the examples above and the other groups in the examples are the least successful. In all groups the expressions during the talk progress towards the scientific view.

\section{Understanding of relationships between different organization levels}

All groups manage to move between different organization levels. For example, they reached consensus on why the parents must be heterozygote in respect to disposition for freckles. In the last sentence of this excerpt student 2:4 expresses the scientific idea of how recessive traits can manifest themselves.

1 S2:1 Well, one can have a disposition for freckles... or shall we ..., is there something more?

$[\ldots]$

6 S2:4 But shouldn't both [parents] have one recessive [trait]?

7 S2:2 Because they should..?

$8 \mathrm{~S} 2: 4$ [inaudible] if freckles are dominant?

9 S2:2 Yes...

10 S2:4 Do both parents have to have..?

$11 \mathrm{~S} 2: 2 \mathrm{Mm}$...

12 S2:3 If they have different, if one of them has [a] dominant [trait]? Then the dominant will take over?

$13 \mathrm{~S} 2: 1 \mathrm{Mm} .$.

$14 \mathrm{~S} 2: 2$ Yes, smart.

$\mathbf{1 5}$ S2:4 But if you have the recessive [trait], then you have to have two? Or? Even if it comes from both parents, it doesn't matter if it only comes from one parent.

The task included several opportunities to make connections between concepts from different organization levels. An example is the relationship between DNA, chromosomes, mitosis, fertilized egg and child. All four groups were more or less able to make the connections between these. There is an example of such a discussion in the next excerpt.

1 S3:1 But then, when the egg is fertilized [...] it copies itself into normal cells.

$2 \mathrm{~S} 3: 3$ Yes.

3 S3:2 Is it where we should write that one gets both the recessive traits?

Another possibility to make connections between concepts from different organisation levels in this task is how the genes are related to characteristics. A striking similarity between all four discussions is the lack of talk about the relation between protein synthesis and the individuals' characteristics. The need for better understanding is often posed as questions, as can be seen in many of the previous excerpts regarding all three research questions. Examples in the results were collected from all four groups. All participants contributed to the discussions.

\section{Discussion}

This assignment succeeded in making the students express their understanding of the subject-specific vocabulary, which was the topic of the first research question. During the work with the assignment, it became obvious to many of the participating students that they did not completely understand the different concepts. This is in accordance with previous research (Bahar, Johnstone \& Hansell, 1999). Mostly, all students were involved in the discussions, which often included references to the literature. The need for a better understanding is often posed as questions. Many times the participants manage to develop the scientific language in their talk, like in the first excerpt of the results regarding subject specific vocabulary and also the first excerpt regarding how gametes arise. 
The problem to understand the process of meiosis, or reduction division, is discussed in all groups and during the discussion they all made it more or less clear how gametes differ from somatic cells. The subject is reported as difficult (Bahar, Johnstone \& Hansell, 1999; Knippels, 2002), mitosis and meiosis are subtly different and the fact that they are often taught side by side can contribute to the confusion (Ausubel, Novak \& Hanesian, 1978). It is necessary to understand reduction division to be able to explain how the child can have characteristics which do not appear in the parents' generation and why the offspring have hereditary characteristics from both parents. This was not clear for all participants in the beginning, but became clearer during the discussions. One example of how the groups develop their discussion is showed in "How do gametes arise?" Only one of the four groups did not manage to clarify the difference between the two types of cell division, partly because they ran out of time. One student in that group develops her scientific language during the discussion. Relationships between concepts from different organization levels are discussed in connection with DNA, chromosomes, cell division and individuals. This is handled well by the groups and two of the four groups have a complete picture and the other two groups are well on their way after the discussion. In regards to proteins, none of the groups discussed any relation to cells or macroscopic characteristics. The groups did not find any reasons to relate protein synthesis to anything but the necessary molecules for this process. Maybe freckles are too difficult to relate to proteins, but there can be other reasons as well. It is in accordance with earlier studies (Bahar, Johnstone \& Suttcliffe, 1999), where there was a weak connection between phenotype and gene. The reason might be the separation of molecular genetics from Mendelian genetics in many text books (Knippels, 2002). This was the case for the literature used by the students in this study and may be an alternative explanation.

\section{CONCLUSION}

Peer discussions during the construction of a concept map can contribute to improvement on how students talk about the three genetic difficulties subject-specific vocabulary, cell division and relations between concepts from different organization levels. This kind of small group discussion can facilitate for teachers to clarify what part of the scientific content the students grasp and if there are parts that need further teaching. Almost all participants in the study contributed readily to the discussion, even though this group of students did not have science as their main subject. To make students aware of the importance of their own contribution to the discussion, and to evaluate how their consciousness changes the discussion, is a question for further research.

\section{ACKNOWLEDGEMENTS}

Thanks to Thomas Gustafsson and his group of students who let me participate in their lessons and who also had an active part in the assignment.

\section{REFERENCES}

Ausubel, D. P., Novak, J. D., \& Hanesian, H. (1978). Educational psychology : A cognitive view (2nd ed.). New York, NY: Holt, Rinehart and Winston cop.

Bahar, M., Johnstone, A. H., \& Hansell, M. H. (1999). Revisiting learning difficulties in biology. Journal of Biological Education, 33(2), 84-86.

Bahar, M., Johnstone, A. H., \& Suttcliffe, R. G. (1999). Investigation of students' cognitive structure in elementary genetics through word association tests. Journal of Biological Education, 33(3), 134-141.

Dreyfus, A., \& Jungwirth, E. (1989). The pupil and the living cell: A taxonomy of dysfunctional ideas about an abstract idea. Journal of Biological Education, 23(1), 49-55.

Hake, R. R. (1998). Interactive-engagement versus traditional methods: A six-thousand-student survey of mechanics test data for introductory physics courses. American Journal of Physics, 66, 64-74.

Johnstone, A. H. (1991). Why is science difficult to learn? things are seldom what they seem. Journal of Computer Assisted Learning, 7(2), 75-83. 
Knippels, M. (2002). Coping with the abstract and complex nature of genetics in biology education : The yo-yo learning and teaching strategy. Doctoral dissertation.

Marbach-Ad, G., \& Stavy, R. (2000). Students' cellular and molecular explanations of genetic phenomena. Journal of Biological Education, 34(4), 200-205.

Mortimer, E. F., \& Scott, P. (2003). Meaning making in secondary science classrooms. Buckingham, England: Open University Press.

Novak, J. D., \& Cañas, A. J. (2008). The theory underlying concept maps and how to construct and use them. Retrieved March 14, 2009 from Florida Institute for Human and Machine Cognition Web site:: http://www.bv229.k12.ks.us/biophilia/KABT/g2c/TheoryUnderlyingConceptMapsHQ.pdf

Osborne, J. (2010). Arguing to learn in science: The role of collaborative, critical discourse. Science, 328(5977), 463-466.

Smith, M. K., Wood, W. B., Adams, W. K., Wieman, C., Knight, J. K., Guild, N., et al. (2009). Why peer discussion improves student performance on in-class concept questions. Science, 323(5910), 122.

Wellington, J. J., \& Osborne, J. (2001). Language and literacy in science education. Buckingham, England: Open University Press,.

Wood-Robinson, C., Lewis, J., \& Leach, J. (2000). Young people's understanding of the nature of genetic information in the cells of an organism. Journal of Biological Education, 35(1), 29-36. 